\title{
Therapeutic Update on Huntington's Disease: Symptomatic Treatments and Emerging Disease-Modifying Therapies
}

\author{
Deepa Dash ${ }^{1,2,3} \cdot$ Tiago A. Mestre ${ }^{1,2,3}$ D \\ Published online: 23 July 2020 \\ (C) The American Society for Experimental NeuroTherapeutics, Inc. 2020
}

\begin{abstract}
Huntington's disease (HD) is a monogenic neurodegenerative disorder that presents with progressive motor, behavior, and cognitive symptoms leading to early disability and mortality. HD is caused by an expanded CAG repeats in exon 1 of the huntingtin (HTT) gene. The corresponding genetic test allows a clinical, definite diagnosis in life and the identification of a fully penetrant mutation carrier in a premanifest stage. In addition to the development of symptomatic treatments that attempt to address unmet care needs such as apathy, irritability, and cognition, novel therapies that target pathways specific to HD biology are being developed with the intent of slowing disease progression. Among these approaches, HTT protein lowering therapies hold great promise. There are currently active programs using antisense oligonucleotides (ASOs), RNA interference, smallmolecule splicing modulators, and zinc-finger protein transcription factor. Except for ASOs and RNA interference approaches, the remaining therapeutic strategies are at a preclinical stage of development. While the current therapeutic landscape in HD may bring an unparalleled change in the lives of people with HD and their families with the first-ever disease-modifying therapy, the evaluation of these therapies requires novel tools that enable a more efficient and expedited discovery and evaluative process. Examples are biomarkers targeting the HTT protein to measure target engagement or disease progression and rating scales more sensitive to the earliest clinical changes. These tools will be instrumental in the next phase of disease-modifying clinical trials in HD likely to target the phenoconversion period of the disease, including the prodromal HD stage.
\end{abstract}

Key Words Huntington's disease $\cdot$ chorea $\cdot$ disease modification $\cdot$ therapies

\section{Introduction}

Huntington's disease (HD) is an autosomal-dominant neurodegenerative disorder with an estimated worldwide prevalence of 2.7 per 100,000 [1], with a lower prevalence in Asia [1], and prevalence as high as 12.3 to 13.7 per 100,000 in countries like Canada and the UK $[2,3]$. HD is caused by an

Electronic supplementary material The online version of this article (https://doi.org/10.1007/s13311-020-00891-w) contains supplementary material, which is available to authorized users.

Tiago A. Mestre

tmestre@toh.ca

1 Brain and Mind Research Institute, University of Ottawa, Ottawa, Ontario, Canada

2 The Ottawa Hospital Research Institute, Ottawa, Ontario, Canada

3 Parkinson Disease and Movement Disorders Centre, Division of Neurology, Department of Medicine, The Ottawa Hospital and the University of Ottawa, Ottawa, Canada expanded CAG repeats in exon 1 of the huntingtin (HTT) gene, which leads to the synthesis of a mutant form of the huntingtin protein (mHTT) [4]. The availability of a clinical test to identify the gene mutation allows to confirm a clinical diagnosis of $\mathrm{HD}$ in life (CAG $n \geq 36$ ) and to identify those individuals that carry the mutation and will develop the disease (CAG $n \geq 40$ ). A longer CAG repeat length is associated with an earlier onset and faster clinical progression [5].

The clinical hallmark of the disease is the presence of chorea, together with the nonmotor features of cognitive decline and behavioral changes such as apathy, depression, irritability, anxiety, obsessive/compulsive behaviors and, more rarely, psychosis [6]. Parkinsonism is a later feature in adult-onset HD and a presenting feature in the juvenile form of HD [4]. Symptoms progress relentlessly over time and leads to death in 10-15 years from clinical onset [7]. In the last couple of decades, observational studies highlighted the presence of subtle cognitive and behavioral changes together with structural brain abnormalities many years before the appearance of classic motor features that more commonly allow clinical 
diagnosis $[8,9]$. These findings led to the definition of discrete periods in the natural history of HD in relation to symptom onset. The recent classification proposed by the HD Task Force of the International Parkinson's Disease and Movement Disorder Society established three diagnostic categories (presymptomatic HD, prodromal HD, and manifest HD) according to the presence and severity of motor and cognitive changes [10]. Importantly, each diagnostic category was associated with the potential for the development of novel symptomatic and/or disease-modifying therapies [10].

The drug development approach for HD has undergone a remarkable evolution in recent years. Aside from efforts focused on symptomatic treatment, therapies that target specific aspects of HD biology are being developed and evaluated for the first time for a putative slowing of disease progression. In this review, we provide an update on the advances in the symptomatic treatment of HD and present the growing efforts in disease-modifying therapies, with a particular emphasis on interventions aimed at lowering the level of mHTT in the brain.

\section{Symptomatic Treatment}

The multifaceted clinical presentation of HD makes symptomatic management challenging, with the need for multiple treatments and the intervention of a multispecialty care team. The first systematic review on therapeutic interventions for HD concluded that tetrabenazine (TBZ) is the only drug with evidence for the treatment in HD, specifically for chorea [19]. Consequently, the symptomatic treatment in HD continues to be mostly based on expert opinion, the extrapolation of the best evidence available for other conditions, and good clinical practice recommendations. In this section, we provide an update on the efforts to develop an evidence-based approach to symptom-based treatment in HD divided into its different symptom clusters. (Table 1).

Motor Symptoms Symptomatic therapeutic development has focused primarily on chorea and motor impairment using as outcome measures the Unified Huntington's Disease Rating Scale (UHDRS) total motor score or its chorea items. Chorea is the clinical feature in HD for which most of the therapeutic studies have been conducted [19] and remains the only HD symptom for which there is a formal therapeutic indication. There are no approved treatments for the other motor features.

TBZ is an inhibitor of the vesicular monoamine transporter 2 (VMAT2) and the first drug with an FDA-approved indication for HD. This indication was supported by a 12-week randomized controlled trial (RCT) TETRA-HD [20] that documented a clinically significant reduction of chorea with TBZ compared with placebo, with an adjusted decrease of 3.5 points in the UHDRS chorea subscore [20]. There was no benefit in terms of functional ability [20]. The most common dose-limiting side effects for TBZ were somnolence, insomnia, depressed mood, akathisia, and parkinsonism [20]. More recent studies have demonstrated the longterm efficacy and tolerability of TBZ in patients with HD [21].

Deutetrabenazine (deuTBZ), a deuterated version of TBZ, was recently approved by the FDA for the treatment of chorea in HD. The introduction of a deuterated form of hydrogen molecules in deuTBZ imparts a longer half-life, with less frequent daily dosing and potentially better tolerability than TBZ [22]. With this rationale, the RCT FIRST-HD demonstrated a 12week efficacy with a 2.5-point reduction in the UHDRS chorea subscore compared with placebo and a similar rate of depression, anxiety, and akathisia in deuTBZ and placebo arms [23]. There is no head-to-head comparison study of TBZ and deuTBZ. A network meta-analyses of FIRST-HD and TETRA-HD studies concluded similar antichoreic effect and safety, except for less depression and somnolence with deuTBZ [24]. An indirect treatment comparison reported less neuropsychiatric side effects and risk of akathisia and parkinsonism with deuTBZ compared to TBZ [25].

The overnight switch from TBZ to deuTBZ was safe and well-tolerated in the ARC-HD open-label safety study [26]. The single daily dosing VMAT2 inhibitor valbenazine is under evaluation for the treatment of chorea (NCT04102579, KINECT-HD) [27].

Other interventions have been investigated for the treatment of chorea in HD. Neuroleptics and amantadine were evaluated in small RCTs [28], and the evidence is less robust. In an international survey, TBZ and dopamine-blocking agents were commonly used in clinical practice to treat chorea in HD [29]. There was no consensus regarding the use of amantadine for chorea. Benzodiazepines were found to be useful as an adjunctive therapy for chorea exacerbated by anxiety [30]. As a good clinical practice recommendation, the treatment of chorea should be considered to improve functional ability and not solely to reduce its severity. Because of the progressive nature of the illness, the dose and use of medications needs to be reassessed periodically [30].

Surgical interventions have been considered for severe refractory chorea. HD was at the forefront in human stereotactic neurosurgery, with the first pallidal neurosurgery being conducted in a patient with clinical HD for the relief of chorea [31]. With the advent of neuromodulation, pallidal deep brain stimulation (DBS) has been evaluated in small noncontrolled studies [32-38]. A double-blind, randomized crossover study of pallidal DBS demonstrated a significant improvement in chorea, quality of life, and functional scores at a 6-month follow-up, but not for dystonia [39]. Unfortunately, pallidal DBS can be associated with the worsening of parkinsonism and gait [39-41]. A larger sham-controlled, multicenter RCT (HD-DBS) is currently ongoing to assess the impact of pallidal DBS for chorea and other aspects of the HD motor phenotype (NCT02535884) [42].

Other movement disorders in HD remain orphan therapeutic indications in need of further trials. There is a dearth of 


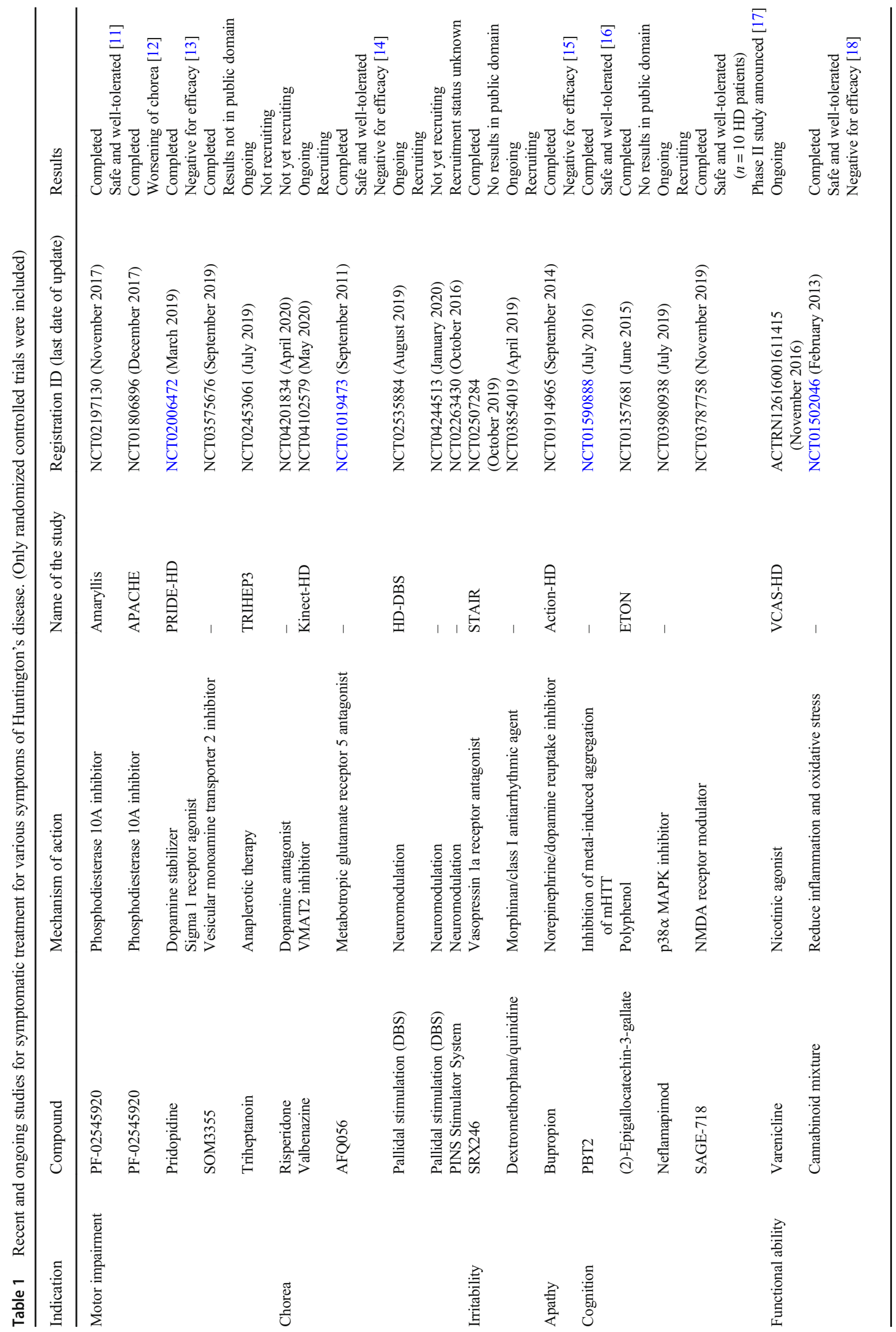


literature to inform evidence-based treatment for parkinsonism or dystonia in HD. For example, dopaminergic agents have been considered for parkinsonism in the juvenile form of HD, but the evidence is based mostly on case reports [43, 44]. More recently, a case series evaluated the use of cannabinoids for the treatment of dystonia in HD with a reported improvement in the UHDRS dystonia items, using a prepost design without a comparator group [45].

Behavioral Symptoms Behavioral changes are a core feature of $\mathrm{HD}$ associated with poor quality of life in patients and a source of stress for relatives and caregivers alongside cognitive impairment [46]. There is very little data from clinical trials to guide the management of behavioral symptoms in HD. In the recent past, buspirone was evaluated in an RCT for the treatment of apathy with negative results [15]. Currently, dextromethorphan/ quinidine and SRX46, a vasopressin 1A receptor antagonist, are being evaluated for irritability (Table 1).

Without contributory evidence from RCTs, guidelines for the treatment of behavioral symptoms in HD are based on expert consensus [47-49]. In depression, psychotherapy and cognitive behavioral therapy could have a role in early milder forms. Serotonin reuptake inhibitors (SSRIs) and serotoninnorepinephrine reuptake inhibitors are the first-line pharmacological options for both depression and anxiety. Although SSRIs can have a role for irritability, the use of sedative antidepressants, neuroleptics, or mood stabilizers is considered in more severe cases. Apathy remains a difficult symptom to treat in HD. A trial of an antidepressant is reasonable, particularly when depression coexists [47].

Cognitive Symptoms The evidence for the treatment of cognitive symptoms is minimal and derives from small RCTs. A Cochrane review of acetylcholinesterase inhibitors for HD included data from two RCTs in a total of $48 \mathrm{HD}$ subjects. It concluded that the efficacy of cholinesterase inhibitors for cognitive dysfunction is unclear [50]. A couple of RCTs are ongoing with the compounds neflamapimod (MAPK inhibition) and SAGE-718 (NMDA receptor modulation). (Table 1).

\section{Emerging Therapies for Disease Modification in HD}

In the past decades, there have been various efforts to identify disease-modifying therapies in HD. Overall, these compounds targeted multiple downstream cellular processes and molecular targets, including oxidative stress, transcriptional dysregulation, mitochondrial dysfunction, and excitotoxicity [51]. Unfortunately, these clinical trials did not result in a diseasemodifying therapy for HD [51].

The field of HD therapeutics lives through promising times as novel interventions targeting proximal pathways in the HD cell pathogenesis, such as the synthesis of mHTT and its intracellular trafficking, are evaluated for a disease-modifying effect. The ability to inhibit the synthesis of mHTT is perhaps the therapeutic strategy with the highest potential for disease modification. Various mHTT-lowering approaches are at a preclinical phase, and a few clinical trials have already started in some programs (Table 2). In the following section, we provide an updated description of various therapeutic development programs aiming at identifying a disease-modifying treatment in HD, with a particular focus on approaches targeting the HTT pathway.

\section{HTT-Targeted Approaches}

The CAG repeat expansion in the HTT gene found in HD leads to the transcription of a pathologically long pre-mRNA and the synthesis of an abnormal and unstable mHTT protein [60]. Although the precise role of mHTT in the pathophysiology of HD is not entirely clear, the overall effect of mHTT is associated with a toxic gain -of-function in various biological functions such as transcription, intracellular signalling, intracellular transport, mitochondrial function, synaptic dysfunction, and even immunity [4]. Different species of mHTT can contribute to its toxic effect from the full-length protein to fragments at $\mathrm{N}$-terminal end, exon 1, expansion proteins from a repeat-associated non-ATG translation mechanism [61]. The relative importance of the different $\mathrm{mHTT}$ species may determine the success of HTT-targeted strategies.

Since the seminal paper of Yamamoto et al. demonstrated that mHTT suppression in HD mouse models could reverse neuropathological and the motor phenotype [62], various therapeutic strategies have been designed to target the HTT pathway to eliminate or, at least, lower the levels of MHTT in the brain. These strategies target the HTT cell lifecycle at the level of the DNA, RNA, or the protein itself. DNA-based strategies include removing the mutated gene from the genome (clustered regularly interspaced short palindromic repeats (CRISPR)-Cas9 gene-editing system) or inhibiting its transcription. RNA-based approaches inhibit the transcription process and synthesis of mHTT, whereas protein-based strategies modulate the mHTT protein homeostasis.

\section{RNA-Targeted Therapies}

The process of HTT synthesis can be modulated by targeting pre-mRNA using antisense oligonucleotides (ASOs), interfering with the splicing process using small-molecule splicing modulators or inhibiting coupling of mRNA to the ribosome using RNA interference (RNAi) strategies. These approaches promote cleavage, enhanced degradation, or translational suppression of mHTT mRNA resulting in a reduction of mHTT protein that may slow disease progression in HD [61]. 


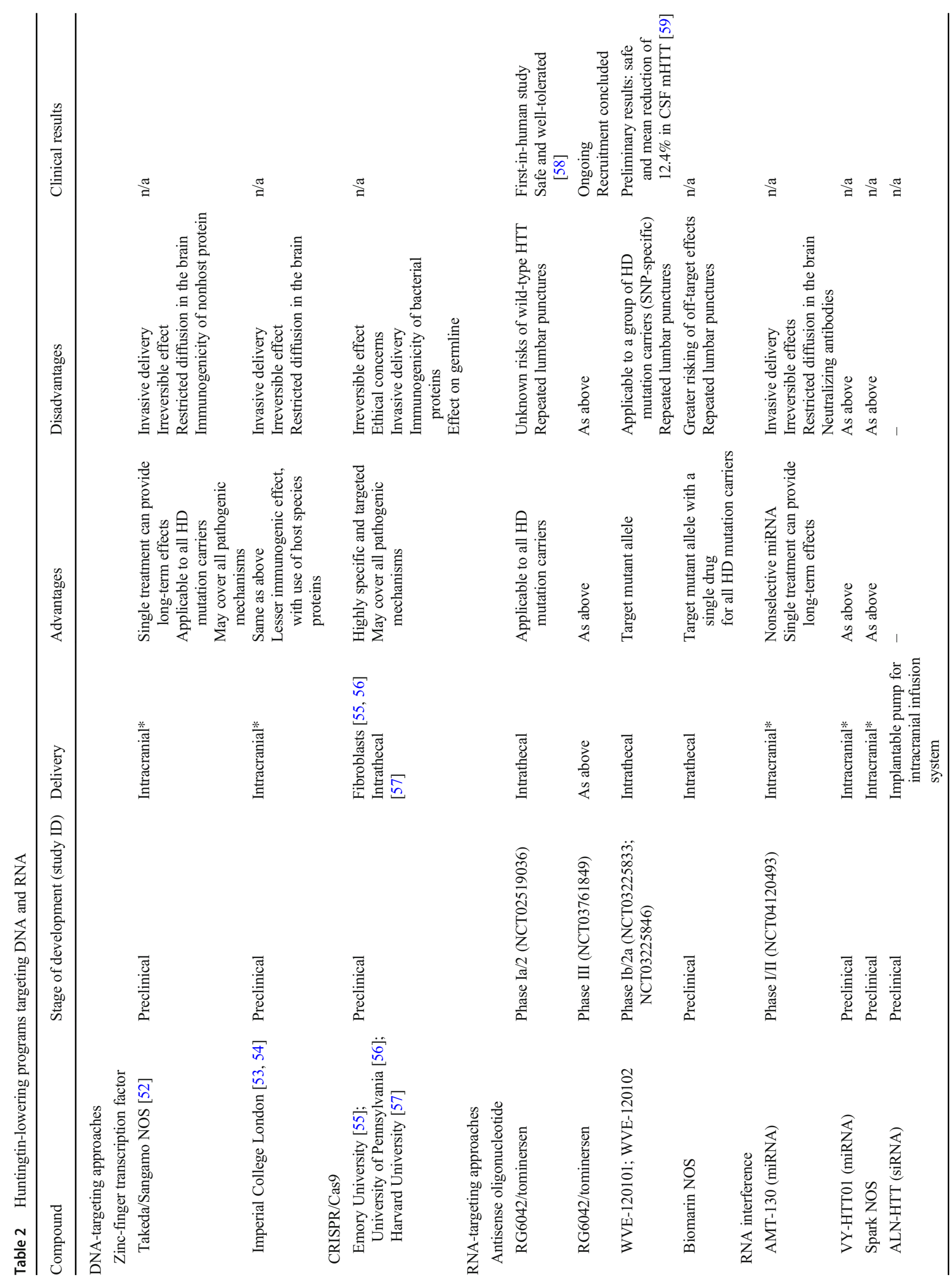


Antisense Oligonucleotides ASOs are synthetic singlestranded synthetic oligonucleotide analogues ranging from 16 to 22 nucleotides that hybridize with complementary RNA sequences and can prevent protein synthesis, alter transcript processing [63], or prevent the mRNA translation with an early degradation via ribonuclease $\mathrm{H}$-mediated hydrolysis [64]. ASOs are classified into those targeting solely the mutated HTT mRNA (allele-specific) or those targeting wild-type and mutated HTT mRNA (nonallele-specific). ASOs have demonstrated reversal of the HD pathology and clinical phenotype in preclinical studies laying the basis of clinical trials for these approaches [65-67].

The first ASO to be tested in clinical studies was the nonallelespecific ASO RG6042, now known as tominersen. Leading up to first-in-human clinical trials, ASOs demonstrated a reduction of up to $80 \%$ of the mHTT mRNA expression and $60 \%$ of the mHTT protein with the rescue of the HD phenotype in various animal models [65-67]. The IONIS-HTTRx study was the firstin-human clinical trial and assessed safety, tolerability, pharmacokinetics, and pharmacodynamics of multiple ascending doses of tominersen up to $120 \mathrm{mg}$ with four monthly intrathecal administration in a total of 46 subjects with early manifest $\mathrm{HD}$ [58]. The pharmacokinetics and pharmacodynamics were conducted on CSF and plasma samples. There was a dose-dependent mean reduction of about $40 \%$ in CSF mHTT concentration at the two highest doses of 90 to $120 \mathrm{mg}$ of tominersen [58], which may correspond to a 55 to $85 \%$ reduction in cortical mHTT and a 20 to $50 \%$ reduction in caudate mHTT [68]. A persistent effect was established in the subsequent 2-month follow-up period. There were no significant safety concerns or dose-limiting toxicity. Post hoc analyses suggested a correlation between a reduction in CSF mHTT and improvement in a composite UHDRS score. However, these results should be interpreted with caution as the trial was not primarily designed to document a clinical benefit. A phase III multinational, multicenter trial enrolling more than 800 subjects in early manifest HD is currently ongoing to provide confirmatory efficacy data for tominersen as a diseasemodifying therapy (GENERATION-HD1, NCT03761849) [69].

Allele-specific ASOs have also entered the clinical trial phase. Allele specificity is obtained by targeting individual single nucleotide polymorphisms (SNPs) found in the mutated HTT gene [70]. These SNPs are present in not all but a fraction of the HD population. It is estimated that about two-thirds of the patient population with $\mathrm{HD}$ would be eligible for the two allelespecific ASOs under clinical trials [71]. PRECISION-HD1 (WVE-120101) and PRECISION-HD2 (WVE-120102) are phase Ib/IIa RCTs currently underway in North America and Europe to determine the safety, tolerability, pharmacokinetics, and pharmacodynamics of single and multiple ascending doses of WVE-120101 and WVE-120102 [72, 73]. Preliminary results of the PRECISION-HD2 study do not raise any immediate safety concerns and report a mean reduction of $12.4 \%$ in CSF mHTT across all intervention arms compared with 
placebo [59], which led to the addition of a higher dose arm in both studies. The results of these studies are expected by the end of 2020, and a phase III study is planned.

The intrathecal route of administration of ASOs is associated with a variable brain regional distribution and target engagement. Animal studies have suggested that the administration of IONIS/Roche HTTRx is associated with $\sim 50 \%$ reduction of mHTT in the cortex and $\sim 15$ to $20 \%$ in the caudate nucleus [74]. The clinical effects of this imbalanced brain distribution are not yet fully known. The preferential targeting of cortical areas and a potential more significant rescue of cortical function may result that the disease-modifying effect of an ASO may result in a different HD phenotype, with more motor symptoms and less behavioral/cognitive symptoms [75].

The repeated administration of ASOs may be a challenge for future usage of this agent in clinical practice. Based on preclinical data [65] and modelling of data from IONIS-HTTRx study [58], the initially tested monthly injections in IONIS-HTTRx are now done every 2 to 4 months in GENERATION-HD1 study. The lesser frequency of administration assumes that the associated mean reduction in the levels of mHTT is sufficient to render a clinical effect. One of the mitigating strategies for the reduced CNS permeability of ASOs is the use of peptide conjugates that may allow for a wide CNS distribution with an intravenous administration $[76,77]$. The preliminary testing for these nextgeneration ASOs has started in other neurological disorders such as spinal muscular atrophy [78], but not in HD.

RNA Interference-Based Strategies RNAi strategies target the evolutionarily conserved process of mRNA degradation by small noncoding RNAs [79, 80], leading to translational suppression and reduction of corresponding protein levels. Compared with ASOs, RNAi has a more downstream site of action acting on spliced mRNA in the cytosol. Broadly, RNAi strategies include small-interfering RNA (siRNA), short-hairpin RNA (shRNA), and cloned artificial microRNA (miRNA) [79] that bind to the mRNA of the target gene leading to blockage of translation or an early degradation of the transcript [79].

The main challenge with RNAi strategies is the reduced CNS permeability and cell transduction requiring the use of enhanced delivery methods through chemical modification, liposome formulation, nanoparticles, and viral vectors [79]. The use of viral vectors has been favored in HD. It requires an intracranial injection to enable the stable expression of the RNAi compound in a larger number of cells after a single dose [81, 82]. An adenoassociated virus (AAV) has been used more commonly due to strong and stable gene expression, low immunogenicity, nonpathogenicity, and inability to replicate [79]. These agents may provide long-term mHTT silencing after a single intracranial injection but also raise the concern of irreversible adverse effects. In this context, off-target effects are of greater concern as binding to mRNA sequences in unrelated genes may lead to the downregulation of proteins other than HTT [83].
In HD, the delivery of various mHTT-targeting RNAi strategies into the striatum, putamen, or cerebral ventricles was associated with the reduction of mHTT aggregation and improvement in the experimental HD phenotype and brain pathology $[79,84,85]$. Therapeutic development is at a preclinical stage for almost all RNAi-based strategies (Table 2). The exception is the nonallele-specific miRNA AMT-130 coupled to an AAV5 vector currently being tested in a first-in-human safety sham-controlled randomized trial in early HD (NCT04120493). AMT-130 uses an MRI-guided convention-enhanced delivery system for a single bilateral caudate and putaminal administration. This study will evaluate the temporal profile of AMT-130 concentration in the brain, as well as CSF levels of DNA and miRNA expression [86].

Another compound, the AAV-delivered nonallele-specific RNAi VY-HTT01, has shown the ability to lower HTT mRNA after intracranial administration in nonhuman primates with good tolerance [87]. In a recent study, MRI-guided delivery of VY-HTT01 into the putamen and thalamus resulted in a good distribution with a dose-dependent, robust, and durable suppression of HTT mRNA and protein [88]. There are plans for a clinical trial with VY-HTT01 in the near future. Vector-associated RNAi strategies raise challenges such as the associated surgical risks of an intracranial route of administration [89] and the limited tissue distribution of a vector-based delivery [90] which, in turn, leads to the need to determine the ideal anatomical site(s) and the optimal number of injections. The development of a viral vector able to cross the blood-brain barrier (BBB) is crucial to overcome these challenges. A RNAi strategy with a systemic administration is appealing. For example, a mutant HTT-specific RNAi coupled with an AAV9 [91] was associated with a reduction of mHTT expression in multiple brain regions and peripheral tissues following a peripheral intravenous injection in mice [92]. This approach is still in its infancy and requires extensive preclinical evaluation.

Small Molecules Targeting RNA An orally bioavailable small molecule that can cross the BBB and modulate the splicing of HTT precursor mRNA is an attractive disease-modifying strategy in HD. Splicing modulators have been shown to reduce HTT levels in HD patient-derived skin cells and neurons, and lead to a $50 \%$ reduction of CSF HTT in two fully humanized mouse HD models [93]. There are plans to conduct firstin-human trials by independent programs. (Table 2).

\section{DNA-Based Approaches}

DNA-based approaches include the inhibition of gene transcription or engineering of the HTT gene through genome editing. DNA-based approaches require the ability to bind to DNA in a specific manner and the action of nucleases, epigenetic modulators, or transcription factors [61]. Zinc-finger protein (ZFP), transcription activator-like effector (TALE), and CRIPSR/Cas9 
system may have applicability to HD [61]. However, very few studies have been conducted so far (Table 2).

Zinc-Finger Protein ZFPs are engineered to target specifically the expanded CAG repeat of the HTT gene and can be coupled to transcription repressor or a nuclease effector domain to cleave DNA [94]. In HD, the ZFPs have been used as transcription repressors. Preclinical data show that ZFPs can reduce mHTT levels, HTT protein aggregates and reverse an HD-like behavioural phenotype in a mice model [53]. Similar findings were reported in patient fibroblasts, stem-cell-derived human neurons with high selectivity for the mutated HTT gene [95]. This study is part of an ongoing therapeutic development pipeline [52] that has not reached a clinical phase. As with RNAi strategies, the therapeutic delivery of ZFPs requires a viral vector and an intracranial administration. Another potential limitation of ZFPs therapeutics is the production of non-native proteins that can trigger inflammatory and immune reactions [96].

Transcription Activator-Like Effector TALEs are similar to ZFPs in that they bind to a target DNA sequence and can be coupled with transcription repressors or a nuclease. In contrast with ZFPs, the TALE DNA recognition domain is based on a sequence of amino acid repeats that binds to a specific nucleotide sequence [97]. So far, there is a single proof-of-concept preclinical study conducted in HD-patient derived fibroblasts selective decrease in mHTT expression and aggregation with TALEs [98], and there are no clinical studies or active drug development in the pipeline.

CRISPR/Cas9 System The CRISPR/Cas9 system is a geneediting strategy that involves the highly specific identification of a double-stranded DNA sequence via the CRISPR system followed by an RNA-guided nuclease (Cas9 protein) that causes the breakage and excision of the DNA sequence [97]. For genereplacement approaches applicable to $\mathrm{HD}$, there is a need for a protospacer adjacent motif sequence that allows a specific recognition site in SNP alleles of the mutated HTT gene [99, 100]. Conceptually, the CRISPR/Cas9 system may be used to excise the mHTT gene and replace it with the wild type allele, suppress the mutated allele through the insertion of a missense mutation, or reduce transcription of the HTT gene in a non-allele specific manner, for example, through epigenetic regulation [61]. CRISPR/Cas9 system-based approaches are at very early stages of therapeutic development, with a few proof-of-concept studies in cell cultures of HD patients demonstrating the ability of CRISPR/Cas9 system to excise the mutated allele and prevent the production of the mHTT protein [56, 57, 101].

The fact that DNA-based approaches are the most proximal therapeutic target in the mHTT pathway makes them a powerful disease-modifying strategy for HD. DNA-based approaches like the CRISPR/Cas9 system can suppress any pathological species of mHTT and theoretically modify the germline, raising ethical concerns when considering research with this approach. Currently, there is a ban on CRISPR/Cas9related research on germline in most countries.

Potential roadblocks in the development of DNA-based approaches include the immunogenicity of bacterial proteins or of new edited genes, and off-target effects with irreversible changes in other genes that can be associated with severe side effects such as cancer [102-104]. The CRISPR/Cas9 system is conceptually more straightforward in design and delivery compared to ZFP or TALE-based approaches, but the risk of off-target effects may be higher [104].

\section{HTT Modulation}

An alternative approach to mitigate the cellular effects of mHTT is to promote the clearance or inhibit aggregation of the HTT protein. PBT2 and selisistat are examples of interventions tested in clinical trials with negative results leading to the suspension of drug development programs (Table 3).

PBT2 is an 8-hydroxyquinoline transition metal ligand acting as a cellular chaperone. Although initial preclinical studies demonstrated a reduction of aggregated HTT in a mouse model [109], the clinical development of PBT2 targeted a symptomatic effect for cognition. A phase II RCT was negative for the main composite cognitive score [16]. FDA issued a Partial Clinical Hold due safety concerns based on nonclinical data, and the clinical development of PBT2 was halted since then [110]. Selisistat is a selective silent information regulator T1 inhibitor postulated to promote clearance of mHTT [111-113]. Two double-blind RCTs were conducted to assess the safety, tolerability, and efficacy of selisistat on motor disability, cognition, and functional capacity $[105,106]$. The first exploratory study had only a 14-day treatment period, whereas the second was a 12 -week study $[105,106]$. There were no clinically relevant changes in the UHDRS, and aside from a reversible increase in liver function tests, no other safety concerns were documented. Changes in peripheral soluble mHTT were evaluated in the 12-week study that did not result in a consistent and significant finding [106].

\section{Immunomodulation (Table 3)}

In recent years, there was a growing interest in the role of aberrant immune response and other inflammatory mechanisms in the underlying pathogenesis of HD secondary to the presence of mHTT protein [114-119], leading to further neurodegeneration. Compounds with potential immunomodulating effects have been considered for disease modification in HD. Laquinimod and semaphorin 4AD (SEMA4D) are two recent examples. Laquinimod is an oral synthetic derivative of linomide repurposed from multiple sclerosis. Laquinimod was evaluated in a phase II placebo-controlled RCT (LEGATO-HD) study, which was negative for a change in the total motor score of the 
Table 3 Clinical development of other therapies for disease modification in HD according to the proposed mechanism of action. (HTT-based approaches were excluded)

\begin{tabular}{|c|c|c|c|c|c|}
\hline Compound & Mechanism of action & Name of the study & $\begin{array}{l}\text { Registration ID (last date of } \\
\text { update) }\end{array}$ & $\begin{array}{l}\text { Study } \\
\text { phase }\end{array}$ & Results \\
\hline \multicolumn{6}{|c|}{ Huntingtin protein homeostasis } \\
\hline PBT2 & $\begin{array}{l}\text { Metal-protein } \\
\text { attenuating compound }\end{array}$ & Reach2HD & NCT01590888 (July 2016) & II & $\begin{array}{l}\text { Completed } \\
\text { Negative for efficacy [16] }\end{array}$ \\
\hline Selisistat & Sirtuin-1 inhibition & $\begin{array}{l}\text { Paddington } \\
-\end{array}$ & $\begin{array}{l}\text { NCT01485952 (November 2015) } \\
\text { NCT01521585 (November 2015) }\end{array}$ & $\begin{array}{l}\text { I } \\
\text { II }\end{array}$ & $\begin{array}{l}\text { Completed } \\
\text { Negative for efficacy [105, } \\
106]\end{array}$ \\
\hline \multicolumn{6}{|c|}{ Immunomodulation } \\
\hline $\begin{array}{l}\text { Semaphorin } \\
\text { 4AD }\end{array}$ & Monoclonal antibody & SIGNAL & NCT02481674 (May 2020) & II & $\begin{array}{l}\text { Ongoing } \\
\text { Not recruiting }\end{array}$ \\
\hline Laquinimod & $\begin{array}{l}\text { Nf-kb inhibition } \\
\text { Cytokine release }\end{array}$ & LEGATO-HD & NCT02215616 (May 2020) & II & $\begin{array}{l}\text { Completed } \\
\text { Negative for efficacy [107] }\end{array}$ \\
\hline \multicolumn{6}{|l|}{ Other } \\
\hline PF-02545920 & $\begin{array}{c}\text { Phosphodiesterase } \\
10 \mathrm{~A} \text { inhibition }\end{array}$ & $\begin{array}{l}\text { APACHE } \\
\text { Amaryllis }\end{array}$ & $\begin{array}{l}\text { NCT01806896 (December 2017) } \\
\text { NCT02197130 (December 2017) }\end{array}$ & II & $\begin{array}{l}\text { Completed } \\
\text { Negative for efficacy }[11,12]\end{array}$ \\
\hline Nilotinib & $\begin{array}{l}\text { Bcr-Abl tyrosine kinase } \\
\text { inhibitor }\end{array}$ & Tasigna HD & NCT03764215 (February 2020) & $\mathrm{Ib}$ & $\begin{array}{l}\text { Ongoing } \\
\text { Recruiting }\end{array}$ \\
\hline Cysteamine & Multiple mechanisms & CYST-HD & NCT02101957 (April 2014) & $\mathrm{II} / \mathrm{III}$ & $\begin{array}{l}\text { Completed } \\
\text { Negative for efficacy [108] }\end{array}$ \\
\hline SBT-20 & Mitochondrial function & CHALLENGE-HD & $\begin{array}{l}\text { EUCTR2016-003730-25-NL } \\
\quad \text { (February 2018) }\end{array}$ & $\mathrm{Ia} / \mathrm{II}$ & $\begin{array}{l}\text { Ongoing } \\
\text { Not recruiting }\end{array}$ \\
\hline Fenofibrate & $\begin{array}{l}\text { Transcriptional co- } \\
\text { activator }(\mathrm{PGC}-1 \alpha)\end{array}$ & - & NCT03515213 (March 2019) & II & $\begin{array}{l}\text { Ongoing } \\
\text { Not recruiting }\end{array}$ \\
\hline Resveratrol & Sirtuin-1, PGC-1 $\alpha$ modulator & - & NCT02336633 (February 2020) & - & $\begin{array}{l}\text { Completed } \\
\text { No results in public domain }\end{array}$ \\
\hline
\end{tabular}

UHDRS, despite the reduced rate of caudate atrophy and wholebrain atrophy in the laquinimod arm [107]. SEMA4D is a transmembrane signalling protein that interacts with neuroinflammation processes and leads to activation of microglia and disruption of BBB [120, 121]. A monoclonal antibody to SEMA4D (VX15/2503) is currently being evaluated in the SIGNAL trial, a phase II RCT aiming to assess the effect on delaying the onset of clinical HD or the progression of clinical symptoms and signs in early $\mathrm{HD}$ and at a late prodromal stage [122]. Preliminary trial data suggest that VX15/2503 may have a positive effect on imaging outcomes with a lesser reduction of atrophy and metabolic activity in the brain [123]. Results of clinical outcomes are yet to be known.

\section{Considerations for Disease-Modifying Therapies in HD}

The advent of therapies targeting proximal pathways of HD biology is promising. Regardless of the outcome of the GENERATION-HD1 trial and potential identification (or not) of the first disease-modifying therapy in HD, it is inevitable that other human clinical trials for disease modification in HD will be conducted to find more effective treatments, with less invasive routes of administration.

An important question related to HTT-lowering therapies is the requirement for allele specificity or not, mostly in terms of their safety. Data gathered so far is inconclusive regarding allele-specific approaches being potentially safer as they only target the mHTT. While a knockout mouse model for normal HTT does not survive past embryonic development [124, 125], and the absence of normal HTT in an HD preclinical model has been associated with a worsening phenotype [126, 127], the partial suppression of HTT seems to be safe in a rhesus macaque model [128]. The short-term safety data from human studies of nonallele-specific approaches did not raise relevant issues [58]. The observed reduction of around $40 \%$ of CSF HTT levels in IONIS-HTTRx study [58] is less than the $50-75 \%$ threshold of safety in preclinical models [129]. Nevertheless, the long-term safety of nonallele-specific therapies needs to be determined. Allele specificity dictates the development and implementation of novel HTT-lowering therapies. Allele-specific approaches have a higher cost associated with the independent development of different compounds targeting different groups of people with HD and the need for regulatory approval of each agent compared to the nonallele-specific approach. Nonallele-specific approaches 
have the advantage of potentially being applicable to all patients with HD [130].

A significant challenge to a novel disease-modifying therapy in HD is the feasibility of its implementation and associated costs. For example, the need for repeated intrathecal administration of ASOs [131] is deemed to put pressure on existing health care systems. Significant investment will be necessary for the development of clinical expertise and infrastructure for the long-term administration of a treatment like ASOs. The societal cost of the treatment is not established. As an example, the cost of nusinersen, an ASO approved for the treatment of spinal muscular atrophy, amounts to approximately USD $\$ 72,000-130,000$ in the first year of treatment and USD \$36,000-65,000 annually thereafter [132].

The possibility to conduct a disease-modifying trial in subjects at a premanifest/prodromal stage will begin to be seriously considered to intervene earlier in the disease when neurodegeneration is less and rescue potential larger. Although the ease with which subjects can be diagnosed before the onset of clinical symptoms places HD as an ideal model of neurodegenerative disease to develop disease-modifying therapies, trials in premanifest or prodromal stages raise tremendous challenges for study design. One crucial question is the duration of the study. HD is a slowly progressive disease, and the ability to identify a significant therapeutic effect could mean a very long trial with prohibitive costs and considerable attrition risk. Strategies to optimize such design include small proofof-concept studies to identify the interventions with a better target engagement for disease modification and enrichment strategies to include those subjects closer to phenoconversion. The latter implies a staging system of the natural history of HD using both clinical and biomarker data as explicit and feasible criteria to define HD stages [133]. In turn, these stages could be used to define which populations to include in a trial and to treat in the future, if a disease-modifying therapy is approved for premanifest/prodromal HD. Finally, the ability to monitor disease progression beyond currently available clinical outcomes is necessary as individuals in a prodromal phase have minimal clinical features not captured by current clinical rating scales. The HD field is making significant efforts to address these challenges, with the development of biomarkers and clinical rating scales to capture the very early clinical changes in HD. Many of these efforts are being coordinated by the HD-Regulatory Science Consortium (Critical Path Institute/CHDI Foundation) that congregate academia, industry, and regulatory agencies with the goals of enhancing the regulatory path for emerging therapies for HD [133]. The Functional Rating Scale 2.0 and Huntington disease cognitive assessment battery (HD-CAB) are examples of new clinical outcome measures developed for use in clinical trials to capture changes in premanifest and early-manifest HD [133]. Also, a series of nonclinical candidate biomarkers have been put forward to aid therapeutic development. Imaging biomarkers include MRI-based caudate, white matter, whole-brain volumes, white matter integrity measured by DTI-MRI, nuclear imaging with PET using tracers for mHTT or PDE10, and quantification of myoinositol, NAA through MR spectroscopy [133]. Wet biomarkers include the quantification of CSF mHTT, total HTT, neurofilament light protein (NfL), and plasma NfL. Among these, volumetricbased imaging of the caudate/putamen consistently shows the ability to track disease progression many years before motor phenoconversion [9, 134-136] and could be used as enrichment criteria or to track disease progression. The group of biomarkers tracking mHTT is very appealing in the context of HTT-lowering clinical trials [137]. CSF mHTT was already used in the IONIS-HTTRx trial [58] and was the result of the availability of a novel immunoassay validated by regulatory standards for its ability to measure mHTT in picomolar concentrations [138]. A series of clinical correlation studies showed that CSF mHTT level was higher in manifest HD compared with premanifest mutation carriers and an association with measures of clinical severity [139], clinical disease progression, and the 5-year onset probability [140]. Although CSF mHTT is not a direct measure of brain mHTT levels, data from animal studies provide evidence that CSF mHTT may relate to mHTT being released from dying neurons [139]. Another approach to measure mHTT in HD is through PET imaging. The PET radioligand CHDI-00485180 for mHTT is under evaluation in both manifest and premanifest HD [141]. An mHTT PET could help to document the regional differences in the effect of ASOs or other HTT-lowering agents at a proof-of-concept stage of clinical development and as exploratory efficacy outcomes.

More recently, neuronal cytoskeleton components such as $\mathrm{NfL}$ and tau were proposed as markers of neurodegeneration in HD [142, 143]. For NfL, the validity of using plasma has been explored, which could represent a less invasive and safer procedure compared with a CSF-sourced biomarker. Plasma NfL levels showed a good correlation with CSF levels [137] and a fair correlation with brain atrophy, cognitive decline rates, and phenoconversion [144]. An observational study (HDClarity, clinicaltrials.gov NCT02855476) is currently underway to aid in the development of wet biomarkers in HD populations.

\section{Final Remarks}

The advances in the understanding of HD pathogenesis led to the current therapeutic landscape in which different strategies aim to lower the levels of the pathogenic mHTT protein and its biological effects. ASOs are already in a phase of clinical trials, and the ongoing trial GENERATION-HD1 may dramatically change the management of HD in the near future. For the vast majority of other HTT-lowering therapies, the 
current preclinical development may be followed by human clinical trials. Regardless of the results of ongoing clinical trials, the implementation of more robust molecular and imaging biomarkers, and more sensitive clinical scales are instrumental for the next clinical trials in HD. It is expected that not only early HD patients but also a prodromal HD population will take part in these trials.

Required Author Forms Disclosure forms provided by the authors are available with the online version of this article.

\section{References}

1. Harper P. The epidemiology of Huntington's disease. Hum Genet. 1992;89(4):365-376.

2. Fisher ER, Hayden MR. Multisource ascertainment of Huntington disease in Canada: prevalence and population at risk. Mov Disord . 2014;29(1):105-114.

3. Evans SJW, Douglas I, Rawlins MD, Wexler NS, Tabrizi SJ, Smeeth L. Prevalence of adult Huntington's disease in the UK based on diagnoses recorded in general practice records. J Neurol Neurosurg Psychiatry. 2013;84(10):1156-1160.

4. Bates GP, Dorsey R, Gusella JF, Hayden MR, Kay C, Leavitt BR, et al. Huntington disease. Nat Rev Dis Primer. 2015;1:15005.

5. Langbehn DR, Brinkman RR, Falush D, Paulsen JS, Hayden MR, International Huntington's Disease Collaborative Group. A new model for prediction of the age of onset and penetrance for Huntington's disease based on CAG length. Clin Genet. 2004;65(4):267-277.

6. van Duijn E, Craufurd D, Hubers AAM, Giltay EJ, Bonelli R, Rickards H, et al. Neuropsychiatric symptoms in a European Huntington's disease cohort (REGISTRY). J Neurol Neurosurg Psychiatry. 2014;85(12):1411-1418.

7. Keum JW, Shin A, Gillis T, Mysore JS, Abu Elneel K, Lucente D, et al. The HTT CAG-Expansion Mutation Determines Age at Death but Not Disease Duration in Huntington Disease. Am J Hum Genet. 2016;98(2):287-298.

8. Biglan KM, Zhang Y, Long JD, Geschwind M, Kang GA, Killoran A, et al. Refining the diagnosis of Huntington disease: the PREDICT-HD study. Front Aging Neurosci. 2013;5:12.

9. Tabrizi SJ, Langbehn DR, Leavitt BR, Roos RA, Durr A, Craufurd D, et al. Biological and clinical manifestations of Huntington's disease in the longitudinal TRACK-HD study: cross-sectional analysis of baseline data. Lancet Neurol. 2009;8(9):791-801.

10. Ross CA, Reilmann R, Cardoso F, McCusker EA, Testa CM, Stout JC, et al. Movement Disorder Society Task Force Viewpoint: Huntington's Disease Diagnostic Categories. Mov Disord Clin Pract. 2019;6(7):541-546.

11. Pfizer Amaryllis trial ends in disappointment: no improvement in Huntington's disease symptoms - HDBuzz - Huntington's disease research news. [Internet]. [cited 2020 May 2]. Available from: https://en.hdbuzz.net/229

12. 2016 Conference / CHDI Foundation [Internet]. [cited 2020 May 2]. Available from: https://chdifoundation.org/2016conference/

13. Reilmann R, McGarry A, Grachev ID, Savola J-M, Borowsky B, Eyal E, et al. Safety and efficacy of pridopidine in patients with Huntington's disease (PRIDE-HD): a phase 2, randomised, placebo-controlled, multicentre, dose-ranging study. Lancet Neurol. 2019;18(2):165-176.

14. Reilmann R, Rouzade-Dominguez M-L, Saft C, Süssmuth SD, Priller J, Rosser A, et al. A randomized, placebo-controlled trial of AFQ056 for the treatment of chorea in Huntington's disease. Mov Disord . 2015;30(3):427-431.

15. Gelderblom H, Wüstenberg T, McLean T, Mütze L, Fischer W, Saft C, et al. Bupropion for the treatment of apathy in Huntington's disease: A multicenter, randomised, double-blind, placebo-controlled, prospective crossover trial. Plos One. 2017;12(3):e0173872-e0173872.

16. Huntington Study Group Reach2HD Investigators. Safety, tolerability, and efficacy of PBT2 in Huntington's disease: a phase 2, randomised, double-blind, placebo-controlled trial. Lancet Neurol. 2015;14(1):39-47.

17. Sage Therapeutics Announces Planned Progression of SAGE-718 to Phase 2 in Huntington's Disease and Presentations at the 2019 Annual Meeting of the American College of Neuropsychopharmacology (ACNP) [Internet]. Sage Therapeutics, Inc. [cited 2020 May 2]. Available from: https:// investor.sagerx.com/news-releases/news-release-details/sagetherapeutics-announces-planned-progression-sage-718-phase-2.

18. López-Sendón Moreno JL, García Caldentey J, Trigo Cubillo P, Ruiz Romero C, García Ribas G, Alonso Arias MAA, et al. A double-blind, randomized, cross-over, placebo-controlled, pilot trial with Sativex in Huntington's disease. J Neurol. 2016;263(7):1390-1400.

19. Carlozzi NE, Miciura A, Migliore N, Dayalu P. Understanding the Outcomes Measures used in Huntington Disease Pharmacological Trials: A Systematic Review. J Huntingtons Dis. 2014;3(3):233252

20. Huntington Study Group. Tetrabenazine as antichorea therapy in Huntington disease: a randomized controlled trial. Neurology. 2006;66(3):366-372.

21. Frank S. Tetrabenazine as anti-chorea therapy in Huntington disease: an open-label continuation study. Huntington Study Group/ TETRA-HD Investigators. BMC Neurol. 2009;9:62.

22. Shao L, Hewitt MC. The kinetic isotope effect in the search for deuterated drugs. Drug News Perspect. 2010;23(6):398-404.

23. Huntington Study Group, Frank S, Testa CM, Stamler D, Kayson E, Davis C, et al. Effect of Deutetrabenazine on Chorea Among Patients With Huntington Disease: A Randomized Clinical Trial. JAMA. 2016;316(1):40-50.

24. Rodrigues FB, Duarte GS, Costa J, Ferreira JJ, Wild EJ. Tetrabenazine Versus Deutetrabenazine for Huntington's Disease: Twins or Distant Cousins? Mov Disord Clin Pract. 2017;4(4):582-585.

25. Claassen DO, Carroll B, De Boer LM, Wu E, Ayyagari R, Gandhi $\mathrm{S}$, et al. Indirect tolerability comparison of Deutetrabenazine and Tetrabenazine for Huntington disease. J Clin Mov Disord. 2017;4: 3.

26. Frank S, Stamler D, Kayson E, Claassen DO, Colcher A, Davis C, et al. Safety of Converting From Tetrabenazine to Deutetrabenazine for the Treatment of Chorea. JAMA Neurol. 2017;74(8):977-982.

27. Efficacy, Safety, and Tolerability of Valbenazine for the Treatment of Chorea Associated With Huntington Disease - Full Text View - ClinicalTrials.gov [Internet]. [cited 2020 Apr 16]. Available from: https://clinicaltrials.gov/ct2/show/NCT04102579

28. Mestre T, Ferreira J, Coelho MM, Rosa M, Sampaio C. Therapeutic interventions for symptomatic treatment in Huntington's disease. Cochrane Database Syst Rev. 2009;(3): CD006456.

29. Burgunder J-M, Guttman M, Perlman S, Goodman N, van Kammen DP, Goodman L. An International Survey-based 
Algorithm for the Pharmacologic Treatment of Chorea in Huntington's Disease. PLoS Curr. 2011 ;3:RRN1260.

30. Jankovic J, Roos RAC. Chorea associated with Huntington's disease: to treat or not to treat? Mov Disord . 2014;29(11):1414 1418.

31. Hariz M, Tabrizi S. Patients with Huntington's disease pioneered human stereotactic neurosurgery 70 years ago. Brain J Neurol. 2017;140(9):2516-2519.

32. Fawcett AP, Moro E, Lang AE, Lozano AM, Hutchison WD. Pallidal deep brain stimulation influences both reflexive and voluntary saccades in Huntington's disease. Mov Disord . 2005;20(3):371-377.

33. Hebb MO, Garcia R, Gaudet P, Mendez IM. Bilateral stimulation of the globus pallidus internus to treat choreathetosis in Huntington's disease: technical case report. Neurosurgery. 2006;58(2):E383; discussion E383.

34. Fasano A, Mazzone P, Piano C, Quaranta D, Soleti F, Bentivoglio AR. GPi-DBS in Huntington's disease: results on motor function and cognition in a 72-year-old case. Mov Disord . 2008;23(9): 1289-1292.

35. Garcia-Ruiz PJ, Ayerbe J, del Val J, Herranz A. Deep brain stimulation in disabling involuntary vocalization associated with Huntington's disease. Parkinsonism Relat Disord. 2012;18(6): 803-804.

36. Velez-Lago FM, Thompson A, Oyama G, Hardwick A, Sporrer JM, Zeilman P, et al. Differential and better response to deep brain stimulation of chorea compared to dystonia in Huntington's disease. Stereotact Funct Neurosurg. 2013;91(2):129-133.

37. Zittel S, Moll CKE, Gulberti A, Tadic V, Rasche D, Bäumer T, et al. Pallidal deep brain stimulation in Huntington's disease. Parkinsonism Relat Disord. 2015;21(9):1105-1108.

38. Gonzalez V, Cif L, Biolsi B, Garcia-Ptacek S, Seychelles A, Sanrey E, et al. Deep brain stimulation for Huntington's disease: long-term results of a prospective open-label study. J Neurosurg. 2014;121(1):114-122.

39. Wojtecki L, Groiss SJ, Ferrea S, Elben S, Hartmann CJ, Dunnett $\mathrm{SB}$, et al. A Prospective Pilot Trial for Pallidal Deep Brain Stimulation in Huntington's Disease. Front Neurol. 2015;6:177.

40. Amtage F, Feuerstein TJ, Meier S, Prokop T, Piroth T, Pinsker MO. Hypokinesia upon Pallidal Deep Brain Stimulation of Dystonia: Support of a GABAergic Mechanism. Front Neurol. 2013;4:198.

41. Schrader C, Capelle H-H, Kinfe TM, Blahak C, Bäzner H, Lütjens $\mathrm{G}$, et al. GPi-DBS may induce a hypokinetic gait disorder with freezing of gait in patients with dystonia. Neurology. 2011;77(5): 483-488.

42. Deep Brain Stimulation (DBS) of the Globus Pallidus (GP) in Huntington's Disease (HD) - Full Text View - ClinicalTrials.gov [Internet]. [cited 2020 Apr 3]. Available from: https://clinicaltrials. gov/ct2/show/NCT02535884

43. Low PA, Allsop JL. Huntington's chorea-the rigid form (Westphal variant) treated with 1-DOPA: a case report. Proc Aust Assoc Neurol. 1973;10(0):45-46.

44. Low PA, Allsop JL, Halmagyi GM. Huntington's chorea: the rigid form (Westphal variant) treated with levodopa. Med J Aust. 1974;1(11):393-394.

45. Saft C, von Hein SM, Lücke T, Thiels C, Peball M, Djamshidian A, et al. Cannabinoids for Treatment of Dystonia in Huntington's Disease. J Huntingt Dis. 2018;7(2):167-173.

46. Ho AK, Gilbert AS, Mason SL, Goodman AO, Barker RA. Health-related quality of life in Huntington's disease: Which factors matter most? Mov Disord . 2009;24(4):574-578.

47. Anderson KE, van Duijn E, Craufurd D, Drazinic C, Edmondson M, Goodman N, et al. Clinical Management of Neuropsychiatric Symptoms of Huntington Disease: Expert-Based Consensus
Guidelines on Agitation, Anxiety, Apathy, Psychosis and Sleep Disorders. J Huntingt Dis. 7(4):355-366.

48. Groves M, van Duijn E, Anderson K, Craufurd D, Edmondson MC, Goodman N, et al. An International Survey-based Algorithm for the Pharmacologic Treatment of Irritability in Huntington's Disease. PLoS Curr. 2011;3:RRN1259.

49. Simpson JA, Lovecky D, Kogan J, Vetter LA, Yohrling GJ. Survey of the Huntington's Disease Patient and Caregiver Community Reveals Most Impactful Symptoms and Treatment Needs. J Huntingt Dis. 2016;5(4):395-403.

50. Li Y, Hai S, Zhou Y, Dong BR. Cholinesterase inhibitors for rarer dementias associated with neurological conditions. Cochrane Database Syst Rev. 2015;(3):CD009444.

51. Travessa AM, Rodrigues FB, Mestre TA, Ferreira JJ. Fifteen Years of Clinical Trials in Huntington's Disease: A Very Low Clinical Drug Development Success Rate. J Huntingt Dis. 2017;6(2):157-163.

52. Exciting new Huntingtin lowering tool described - HDBuzz Huntington's disease research news. [Internet]. [cited 2020 Apr 21]. Available from: https://en.hdbuzz.net/275

53. Garriga-Canut M, Agustín-Pavón C, Herrmann F, Sánchez A, Dierssen M, Fillat C, et al. Synthetic zinc finger repressors reduce mutant huntingtin expression in the brain of R6/2 mice. Proc Natl Acad Sci U S A. 2012;109(45):E3136-E3145.

54. Agustín-Pavón C, Mielcarek M, Garriga-Canut M, Isalan M. Deimmunization for gene therapy: host matching of synthetic zinc finger constructs enables long-term mutant Huntingtin repression in mice. Mol Neurodegener. 2016;11(1):64.

55. Yang S, Chang R, Yang H, Zhao T, Hong Y, Kong HE, et al CRISPR/Cas9-mediated gene editing ameliorates neurotoxicity in mouse model of Huntington's disease. J Clin Invest. 2017;127(7): 2719-24.

56. Monteys AM, Ebanks SA, Keiser MS, Davidson BL. CRISPR/ Cas9 Editing of the Mutant Huntingtin Allele In Vitro and In Vivo. Mol Ther J Am Soc Gene Ther. 2017;25(1):12-23.

57. Shin JW, Kim K-H, Chao MJ, Atwal RS, Gillis T, MacDonald ME, et al. Permanent inactivation of Huntington's disease mutation by personalized allele-specific CRISPR/Cas9. Hum Mol Genet. 2016;25(20):4566-4576.

58. Tabrizi SJ, Leavitt BR, Landwehrmeyer GB, Wild EJ, Saft C, Barker RA, et al. Targeting Huntingtin Expression in Patients with Huntington's Disease. N Engl J Med. 2019;380(24):2307-2316.

59. Wave Life Sciences Announces Topline Data and Addition of Higher Dose Cohort in Ongoing Phase 1b/2a PRECISION-HD2 Trial in Huntington's Disease [Internet]. Wave Life Sciences. [cited 2020 Mar 31]. Available from: https://ir.wavelifesciences.com/ news-releases/news-release-details/wave-life-sciencesannounces-topline-data-and-addition-higher. Accessed 31 May 2020

60. A novel gene containing a trinucleotide repeat that is expanded and unstable on Huntington's disease chromosomes. The Huntington's Disease Collaborative Research Group. Cell. 1993;72(6):971-983.

61. Tabrizi SJ, Ghosh R, Leavitt BR. Huntingtin Lowering Strategies for Disease Modification in Huntington's Disease. Neuron. 2019;102(4):899.

62. Yamamoto A, Lucas JJ, Hen R. Reversal of neuropathology and motor dysfunction in a conditional model of Huntington's disease. Cell. 2000;101(1):57-66.

63. Evers MM, Tran H-D, Zalachoras I, Meijer OC, den Dunnen JT, van Ommen G-JB, et al. Preventing formation of toxic N-terminal huntingtin fragments through antisense oligonucleotide-mediated protein modification. Nucleic Acid Ther. 2014;24(1):4-12.

64. Gagnon KT, Pendergraff HM, Deleavey GF, Swayze EE, Potier P, Randolph J, et al. Allele-selective inhibition of mutant huntingtin 
expression with antisense oligonucleotides targeting the expanded CAG repeat. Biochemistry. 2010;49(47):10166-10178.

65. Kordasiewicz HB, Stanek LM, Wancewicz EV, Mazur C, McAlonis MM, Pytel KA, et al. Sustained therapeutic reversal of Huntington's disease by transient repression of huntingtin synthesis. Neuron. 2012;74(6):1031-1044

66. Southwell AL, Skotte NH, Kordasiewicz HB, Østergaard ME, Watt AT, Carroll JB, et al. In vivo evaluation of candidate allele-specific mutant huntingtin gene silencing antisense oligonucleotides. Mol Ther J Am Soc Gene Ther. 2014;22(12):20932106.

67. Stanek, L.M., Yang, W., Angus, S., Sardi, P.S., Hayden, M.R., Hung, G.H., Bennett, C.F., Cheng, S.H., and Shihabuddin, L.S. (2013). Antisense oligonucleotide-mediated correction of transcriptional dysregulation is correlated with behavioral benefits in the YAC128 mouse model of Huntington's disease. J. Huntingtons Dis. 2, 217-228.

68. Wang N, Gray M, Lu X-H, Cantle JP, Holley SM, Greiner E, et al. Neuronal targets for reducing mutant huntingtin expression to ameliorate disease in a mouse model of Huntington's disease. Nat Med. 2014;20(5):536-541.

69. A Study to Evaluate the Efficacy and Safety of Intrathecally Administered RO7234292 (RG6042) in Patients With Manifest Huntington's Disease - Full Text View - ClinicalTrials.gov [Internet]. [cited 2020 May 1]. Available from: https:// clinicaltrials.gov/ct2/show/NCT03761849

70. Østergaard ME, Southwell AL, Kordasiewicz H, Watt AT, Skotte $\mathrm{NH}$, Doty CN, et al. Rational design of antisense oligonucleotides targeting single nucleotide polymorphisms for potent and allele selective suppression of mutant Huntingtin in the CNS. Nucleic Acids Res. 2013;41(21):9634-9650.

71. Pfister EL, Kennington L, Straubhaar J, Wagh S, Liu W, DiFiglia M, et al. Five siRNAs targeting three SNPs may provide therapy for three-quarters of Huntington's disease patients. Curr Biol CB. 2009;19(9):774-778

72. Safety and Tolerability of WVE-120101 in Patients With Huntington's Disease - Full Text View - ClinicalTrials.gov [Internet]. [cited 2020 May 1]. Available from: https:// clinicaltrials.gov/ct2/show/NCT03225833

73. Safety and Tolerability of WVE-120102 in Patients With Huntington's Disease - Full Text View - ClinicalTrials.gov [Internet]. [cited 2020 May 1]. Available from: https:// clinicaltrials.gov/ct2/show/NCT03225846. Accessed 1 May 2020

74. 2018 Conference | CHDI Foundation [Internet]. [cited $2020 \mathrm{Mar}$ 31]. Available from: https://chdifoundation.org/2018-conference/. Accessed 31 May 2020

75. Mestre TA, Guttman M. The dawn of a new era for neurodegenerative disorders: Huntington's disease leading the way. Mov Disord . 2019;34(9):1301-1302.

76. McNally EM, Leverson BD. Better living through peptideconjugated chemistry: next-generation antisense oligonucleotides. J Clin Invest. 2019;129(11):4570-4571.

77. Benizri S, Gissot A, Martin A, Vialet B, Grinstaff MW, Barthélémy P. Bioconjugated Oligonucleotides: Recent Developments and Therapeutic Applications. Bioconjug Chem. 2019;30(2):366-383.

78. Hammond SM, Hazell G, Shabanpoor F, Saleh AF, Bowerman M, Sleigh JN, et al. Systemic peptide-mediated oligonucleotide therapy improves long-term survival in spinal muscular atrophy. Proc Natl Acad Sci U S A. 2016;113(39):10962-10967.

79. Keiser MS, Kordasiewicz HB, McBride JL. Gene suppression strategies for dominantly inherited neurodegenerative diseases: lessons from Huntington's disease and spinocerebellar ataxia. Hum Mol Genet. 2016;25(R1):R53-R64.

80. Agrawal N, Dasaradhi PVN, Mohmmed A, Malhotra P, Bhatnagar RK, Mukherjee SK. RNA Interference: Biology,
Mechanism, and Applications. Microbiol Mol Biol Rev. 2003;67(4):657-685.

81. Miniarikova J, Zanella I, Huseinovic A, van der Zon T, Hanemaaijer E, Martier R, et al. Design, Characterization, and Lead Selection of Therapeutic miRNAs Targeting Huntingtin for Development of Gene Therapy for Huntington's Disease. Mol Ther Nucleic Acids. 2016;5:e297.

82. Franich NR, Fitzsimons HL, Fong DM, Klugmann M, During MJ, Young D. AAV vector-mediated RNAi of mutant huntingtin expression is neuroprotective in a novel genetic rat model of Huntington's disease. Mol Ther J Am Soc Gene Ther. 2008;16(5):947-956.

83. Jackson AL, Linsley PS. Recognizing and avoiding siRNA offtarget effects for target identification and therapeutic application. Nat Rev Drug Discov. 2010;9(1):57-67.

84. Rodriguez-Lebron E, Denovan-Wright EM, Nash K, Lewin AS, Mandel RJ. Intrastriatal rAAV-mediated delivery of antihuntingtin shRNAs induces partial reversal of disease progression in R6/1 Huntington's disease transgenic mice. Mol Ther J Am Soc Gene Ther. 2005;12(4):618-633.

85. Stanek LM, Sardi SP, Mastis B, Richards AR, Treleaven CM, Taksir T, et al. Silencing mutant huntingtin by adeno-associated virus-mediated RNA interference ameliorates disease manifestations in the YAC128 mouse model of Huntington's disease. Hum Gene Ther. 2014;25(5):461-474.

86. Safety and Proof-of-Concept (POC) Study With AMT-130 in Adults With Early Manifest Huntington Disease - Full Text View - ClinicalTrials.gov [Internet]. [cited 2020 Apr 12]. Available from: https://clinicaltrials.gov/ct2/show/NCT0412049.

87. Inc VT. Voyager Therapeutics Announces Preclinical Data for Huntington's Disease and Amyotrophic Lateral Sclerosis Programs at the Congress of the European Society of Gene and Cell Therapy [Internet]. GlobeNewswire News Room. 2018 [cited 2020 Apr 11]. Available from: http://www.globenewswire.com/ news release/2018/10/16/1621781/0/en/Voyager-TherapeuticsAnnounces-Preclinical-Data-for-Huntington-s-Disease-andAmyotrophic-Lateral-Sclerosis-Programs-at-the-Congress-of-theEuropean-Society-of-Gene-and-Cell-Therapy.html

88. ESGCT 27th Annual Congress In collaboration with SETGyc Barcelona, Spain October 22-25, 2019 Abstracts. Hum Gene Ther. 2019;30(11):A1-A221.

89. Fetcko K, Lukas RV, Watson GA, Zhang L, Dey M. Survival and complications of stereotactic radiosurgery: A systematic review of stereotactic radiosurgery for newly diagnosed and recurrent highgrade gliomas. Medicine (Baltimore). 2017;96(43):e8293.

90. Gray SJ, Woodard KT, Samulski RJ. Viral vectors and delivery strategies for CNS gene therapy. Ther Deliv. 2010t:1(4):517-534.

91. Foust, K.D.; Nurre, E.; Montgomery, C.L.; Hernandez, A.; Chan, C.M.; Kaspar, B.K. Intravascular AAV9 preferentially targets neonatal neurons and adult astrocytes. Nat. Biotechnol. 2009, $27,59-65$

92. Dufour BD, Smith CA, Clark RL, Walker TR, McBride JL. Intrajugular Vein Delivery of AAV9-RNAi Prevents Neuropathological Changes and Weight Loss in Huntington's Disease Mice. Mol Ther. 2014;22(4):797-810.

93. EHDN Newsletter - 35th edition - European Huntington's Disease Network [Internet]. [cited 2020 Apr 21]. Available from: http://www.ehdn.org/ehdn-newsletter-35th-edition/

94. Mittelman D, Moye C, Morton J, Sykoudis K, Lin Y, Carroll D, et al. Zinc-finger directed double-strand breaks within CAG repeat tracts promote repeat instability in human cells. Proc Natl Acad Sci. 2009 Jun 16;106(24):9607.

95. Zeitler B, Froelich S, Marlen K, Shivak DA, Yu Q, Li D, et al. Alleleselective transcriptional repression of mutant HTT for the treatment of Huntington's disease. Nat Med. 2019;25(7):1131-1142. 
96. Wild EJ, Tabrizi SJ. Targets for future clinical trials in Huntington's disease: what's in the pipeline? Mov Disord . 2014;29(11):1434-1445.

97. Malankhanova TB, Malakhova AA, Medvedev SP, Zakian SM. Modern Genome Editing Technologies in Huntington's Disease Research. J Huntingt Dis. 2017;6(1):19-31.

98. Fink KD, Deng P, Gutierrez J, Anderson JS, Torrest A, Komarla A, et al. Allele-Specific Reduction of the Mutant Huntingtin Allele Using Transcription Activator-Like Effectors in Human Huntington's Disease Fibroblasts. Cell Transplant. 2016;25(4): 677-686.

99. Jinek M, Chylinski K, Fonfara I, Hauer M, Doudna JA, Charpentier E. A Programmable Dual-RNA-Guided DNA Endonuclease in Adaptive Bacterial Immunity. Science. 2012;337(6096):816-821.

100. Savić N, Schwank G. Advances in therapeutic CRISPR/Cas9 genome editing. Transl Res J Lab Clin Med. 2016;168:15-21.

101. Xu X, Tay Y, Sim B, Yoon S-I, Huang Y, Ooi J, et al. Reversal of Phenotypic Abnormalities by CRISPR/Cas9-Mediated Gene Correction in Huntington Disease Patient-Derived Induced Pluripotent Stem Cells. Stem Cell Rep. 2017;8(3):619-633.

102. Hsu PD, Scott DA, Weinstein JA, Ran FA, Konermann S, Agarwala V, et al. DNA targeting specificity of RNA-guided Cas9 nucleases. Nat Biotechnol. 2013;31(9):827-832.

103. Yin H, Kauffman KJ, Anderson DG. Delivery technologies for genome editing. Nat Rev Drug Discov. 2017;16(6):387-399.

104. Fan H-C, Chi C-S, Lee Y-J, Tsai J-D, Lin S-Z, Harn H-J. The Role of Gene Editing in Neurodegenerative Diseases. Cell Transplant. 2018;27(3):364-378.

105. Süssmuth SD, Haider S, Landwehrmeyer GB, Farmer R, Frost C, Tripepi G, et al. An exploratory double-blind, randomized clinical trial with selisistat, a SirT1 inhibitor, in patients with Huntington's disease. Br J Clin Pharmacol. 2015;79(3):465-476.

106. Reilmann R, Squitieri F, Priller J, Saft C, Mariotti C, Süssmuth S, et al. N02 Safety And Tolerability Of Selisistat For The Treatment Of Huntington's Disease: Results From A Randomised, Doubleblind, Placebo-controlled Phase Ii Trial. J Neurol Neurosurg Amp Psychiatry. 2014;85(Suppl 1):A102.

107. Reilmann R, Gordon MF, Anderson KE, Feigin A, Tabrizi SJ, Leavitt BR, et al. The Efficacy and Safety Results of Laquinimod as a Treatment for Huntington Disease (LEGATOHD) (S16.007). Neurology. 2019 ;92(15 Supplement):S16.007.

108. Verny C, Bachoud-Lévi A-C, Durr A, Goizet C, Azulay J-P, Simonin C, et al. A randomized, double-blind, placebocontrolled trial evaluating cysteamine in Huntington's disease. Mov Disord . 2017;32(6):932-936.

109. Cherny RA, Ayton S, Finkelstein DI, Bush AI, McColl G, Massa SM. PBT2 Reduces Toxicity in a C. elegans Model of polyQ Aggregation and Extends Lifespan, Reduces Striatal Atrophy and Improves Motor Performance in the R6/2 Mouse Model of Huntington's Disease. J Huntingt Dis. 2012;1(2):211-219.

110. Prana Biotech (PRAN) Announces Partial Clinical Hold on PBT2 [Internet]. [cited 2020 Apr 21]. Available from: https://www. streetinsider.com/Corporate+News/Prana+Biotech+\%28PRAN\% 29+Announces+Partial+Clinical+Hold+on+PBT2/10265824. html. Accessed 21 May 2020

111. Jeong H, Then F, Melia TJ, Mazzulli JR, Cui L, Savas JN, et al. Acetylation targets mutant huntingtin to autophagosomes for degradation. Cell. 2009;137(1):60-72.

112. Pallos J, Bodai L, Lukacsovich T, Purcell JM, Steffan JS, Thompson LM, et al. Inhibition of specific HDACs and sirtuins suppresses pathogenesis in a Drosophila model of Huntington's disease. Hum Mol Genet. 2008;17(23):3767-3775.

113. Smith MR, Syed A, Lukacsovich T, Purcell J, Barbaro BA, Worthge SA, et al. A potent and selective Sirtuin 1 inhibitor alleviates pathology in multiple animal and cell models of Huntington's disease. Hum Mol Genet. 2014;23(11):2995-3007.

114. Faideau M, Kim J, Cormier K, Gilmore R, Welch M, Auregan G, et al. In vivo expression of polyglutamine-expanded huntingtin by mouse striatal astrocytes impairs glutamate transport: a correlation with Huntington's disease subjects. Hum Mol Genet. 2010;19(15):3053-3067.

115. Björkqvist M, Wild EJ, Thiele J, Silvestroni A, Andre R, Lahiri N, et al. A novel pathogenic pathway of immune activation detectable before clinical onset in Huntington's disease. J Exp Med. 2008;205(8):1869-1877.

116. Sapp E, Kegel KB, Aronin N, Hashikawa T, Uchiyama Y, Tohyama K, et al. Early and progressive accumulation of reactive microglia in the Huntington disease brain. J Neuropathol Exp Neurol. 2001;60(2):161-172.

117. Silvestroni A, Faull RLM, Strand AD, Möller T. Distinct neuroinflammatory profile in post-mortem human Huntington's disease. Neuroreport. 2009;20(12):1098-1103.

118. Crotti A, Benner C, Kerman BE, Gosselin D, Lagier-Tourenne C, Zuccato $\mathrm{C}$, et al. Mutant Huntingtin promotes autonomous microglia activation via myeloid lineage-determining factors. Nat Neurosci. 2014;17(4):513-521.

119. Liddelow SA, Guttenplan KA, Clarke LE, Bennett FC, Bohlen CJ, Schirmer L, et al. Neurotoxic reactive astrocytes are induced by activated microglia. Nature. 2017;541(7638):481-487.

120. Okuno T, Nakatsuji Y, Moriya M, Takamatsu H, Nojima S, Takegahara N, et al. Roles of Sema4D-plexin-B1 interactions in the central nervous system for pathogenesis of experimental autoimmune encephalomyelitis. J Immunol Baltim Md 1950. 2010;184(3):1499-1506.

121. Roles of Sema4D-plexin-B1 Interactions in the Central Nervous System for Pathogenesis of Experimental Autoimmune Encephalomyelitis - PubMed [Internet]. [cited 2020 Mar 19]. Available from: https://pubmed.ncbi.nlm.nih.gov/20038643/

122. A Study in Subjects With Late Prodromal and Early Manifest Huntington's Disease (HD) to Assess the Safety, Tolerability, Pharmacokinetics, and Efficacy of Pepinemab (VX15/2503) Full Text View - ClinicalTrials.gov [Internet]. [cited 2020 Mar 19]. Available from: https://clinicaltrials.gov/ct2/show/ NCT02481674

123. Pepinemab (VX15/2503) Neurology | Vaccinex [Internet]. [cited 2020 Mar 19]. Available from: http://www.vaccinex.com/ development-programs/vx15-neurology/. Accessed 19 May 2020

124. Wang G, Liu X, Gaertig MA, Li S, Li X-J. Ablation of huntingtin in adult neurons is nondeleterious but its depletion in young mice causes acute pancreatitis. Proc Natl Acad Sci U S A. 2016;113(12):3359-3364.

125. Auerbach W, Hurlbert MS, Hilditch-Maguire P, Wadghiri YZ, Wheeler VC, Cohen SI, et al. The HD mutation causes progressive lethal neurological disease in mice expressing reduced levels of huntingtin. Hum Mol Genet. 2001;10(22):2515-2523.

126. Van Raamsdonk JM, Pearson J, Rogers DA, Bissada N, Vogl AW, Hayden MR, et al. Loss of wild-type huntingtin influences motor dysfunction and survival in the YAC128 mouse model of Huntington disease. Hum Mol Genet. 2005;14(10):1379-1392.

127. Ambrose CM, Duyao MP, Barnes G, Bates GP, Lin CS, Srinidhi J, et al. Structure and expression of the Huntington's disease gene: evidence against simple inactivation due to an expanded CAG repeat. Somat Cell Mol Genet. 1994;20(1):27-38.

128. Grondin R, Kaytor MD, Ai Y, Nelson PT, Thakker DR, Heisel J, et al. Six-month partial suppression of Huntingtin is well tolerated in the adult rhesus striatum. Brain J Neurol. 2012;135(Pt 4):11971209.

129. Southwell AL, Kordasiewicz HB, Langbehn D, Skotte NH, Parsons MP, Villanueva EB, et al. Huntingtin suppression restores cognitive function in a mouse model of Huntington's disease. Sci 
Transl Med [Internet]. 2018 Oct 3 [cited 2020 Apr 3];10(461). Available from: https://stm.sciencemag.org/content/10/461/ eaar3959

130. Sah DWY, Aronin N. Oligonucleotide therapeutic approaches for Huntington disease. J Clin Invest. 2011 Feb 1;121(2):500-507.

131. Geary RS, Norris D, Yu R, Bennett CF. Pharmacokinetics, biodistribution and cell uptake of antisense oligonucleotides. Adv Drug Deliv Rev. 2015;87:46-51.

132. Two New Treatments for Spinal Muscular Atrophy May Be Clinic... : Neurology Today [Internet]. [cited 2020 Apr 11]. Available from: https://journals.lww.com/neurotodayonline/ fulltext $/ 2019 / 04180 /$ two_new_treatments_for_spinal_muscular_ atrophy_may.8.aspx. Accessed 11 May 2020

133. Huntington's Disease Regulatory Science Consortium (HD-RSC) Inaugural Meeting Summary | Critical Path Institute [Internet]. [cited 2020 May 1]. Available from: https://c-path.org/ huntingtons-disease-regulatory-science-consortium-hd-rscinaugural-meeting-summary/

134. Tabrizi SJ, Scahill RI, Durr A, Roos RA, Leavitt BR, Jones R, et al. Biological and clinical changes in premanifest and early stage Huntington's disease in the TRACK-HD study: the 12month longitudinal analysis. Lancet Neurol. 2011;10(1):31-42.

135. Aylward EH, Nopoulos PC, Ross CA, Langbehn DR, Pierson RK, Mills JA, et al. Longitudinal change in regional brain volumes in prodromal Huntington disease. J Neurol Neurosurg Psychiatry. 2011;82(4):405-410.

136. Paulsen JS, Langbehn DR, Stout JC, Aylward E, Ross CA, Nance $\mathrm{M}$, et al. Detection of Huntington's disease decades before diagnosis: the Predict-HD study. J Neurol Neurosurg Psychiatry. 2008;79(8):874-880.

137. Byrne LM, Rodrigues FB, Johnson EB, Wijeratne PA, De Vita E, Alexander DC, et al. Evaluation of mutant huntingtin and neurofilament proteins as potential markers in Huntington's disease. Sci Transl Med. 2018 12;10(458).
138. Fodale V, Boggio R, Daldin M, Cariulo C, Spiezia MC, Byrne LM, et al. Validation of Ultrasensitive Mutant Huntingtin Detection in Human Cerebrospinal Fluid by Single Molecule Counting Immunoassay. J Huntingt Dis. 2017;6(4):349-361.

139. Southwell AL, Smith SEP, Davis TR, Caron NS, Villanueva EB, Xie $\mathrm{Y}$, et al. Ultrasensitive measurement of huntingtin protein in cerebrospinal fluid demonstrates increase with Huntington disease stage and decrease following brain huntingtin suppression. Sci Rep. 2015;5:12166.

140. Wild EJ, Boggio R, Langbehn D, Robertson N, Haider S, Miller JRC, et al. Quantification of mutant huntingtin protein in cerebrospinal fluid from Huntington's disease patients. J Clin Invest. 2015;125(5):1979-1986.

141. iMagemHTT: FIH Evaluation of Novel Mutant Huntingtin PET Radioligands $\left[{ }^{11} \mathrm{C}\right] \mathrm{CHDI}-00485180-\mathrm{R}$ and $\left[{ }^{11} \mathrm{C}\right] \mathrm{CHDI}-00485626$

- Full Text View - ClinicalTrials.gov [Internet]. [cited 2020 Apr 12]. Available from: https://clinicaltrials.gov/ct2/show/ NCT03810898. Accessed 1 May 2020

142. Constantinescu R, Romer M, Oakes D, Rosengren L, Kieburtz K. Levels of the light subunit of neurofilament triplet protein in cerebrospinal fluid in Huntington's disease. Parkinsonism Relat Disord. 2009;15(3):245-248.

143. Rodrigues FB, Byrne L, McColgan P, Robertson N, Tabrizi SJ, Leavitt BR, et al. Cerebrospinal fluid total tau concentration predicts clinical phenotype in Huntington's disease. J Neurochem. 2016;139(1):22-25.

144. Byrne LM, Rodrigues FB, Blennow K, Durr A, Leavitt BR, Roos RAC, et al. Neurofilament light protein in blood as a potential biomarker of neurodegeneration in Huntington's disease: a retrospective cohort analysis. Lancet Neurol. 2017;16(8):601-609.

Publisher's Note Springer Nature remains neutral with regard to jurisdictional claims in published maps and institutional affiliations. 